\title{
Una lectura teológica del sermón de José María Cos
}

\author{
ARMANDO LAMPE \\ Universidad de Mainz \\ arlampe@yahoo.com
}

\begin{abstract}
Resumen
El presente trabajo hace una lectura teológica de un sermón insurgente de José María Cos y puede ser considerado un capítulo en la historia de la teología en América Latina, un área todavía poco desarrollada y en la que es necesario hacer nuevos estudios. El artículo se inserta en la nueva historiografía que se ha interesado por la religiosidad de los curas insurgentes y resalta la motivación cristiana del padre Cos, quien se había volcado hacia la praxis política de la independencia de México motivado en primera instancia por su fe cristiana. El artículo concluye aseverando que José María Cos forma entonces parte de una larga tradición de sacerdotes políticos en la historia de la Iglesia católica.
\end{abstract}

Palabras clave: independencia de México; Iglesia y clero; José María Cos; discurso retórico; lectura teológica.

\section{A Theological Interpretation of the Sermon by José María Cos}

\begin{abstract}
This paper provides a theological interpretation of an insurgent sermon by José María Cos and may be considered a chapter in the history of theology in Latin America, an area that has scarcely been explored, and where new studies are required. The item is inserted in the new historiography concerned with the religiosity of insurgent priests and highlights the Christian motivation of Father Cos, who had turned to the political praxis of Mexico's independence motivated primarily by his Christian faith. The article concludes by declaring that José María Cos therefore forms part of a long tradition of political priests in the history of the Catholic Church.
\end{abstract}

Key words: Mexico's independence; Church and clergy; José María Cos; rhetorical discourse; theological interpretation.

Fecha de recepción: Fecha de aceptación:

14 de marzo de $2014 \quad 20$ de julio de 2014 


\title{
Una lectura teológica del sermón de José María Cos
}

\author{
Armando Lampe
}

$\mathrm{E}^{1}$ 1 objeto de mi estudio es un sermón del cura insurgente José María Cos. La historiadora Ana Carolina Ibarra (2010) señala que la historiografía tiene que estudiar la religiosidad de los líderes de la independencia de México y dio el ejemplo de ahondar en los motivos y los argumentos que llevaron a los curas a comprometerse con la insurgencia y que se sitúan en el ámbito de la cuestión religiosa. Asimismo, menciona que no conocemos documentos teológicos de los principales curas-líderes que nos puedan ayudar a comprender sus intenciones para lanzarse a una lucha política que podría haberles costado la vida (Ibarra, 2010, p. 41). Una conclusión similar la encontramos en la obra importante de Carlos Herrejón (2003) cuando dice que de los sermones insurgentes "desgraciadamente casi ninguno se imprimió" (p. 317). Contamos ahora con un documento valioso, es decir un sermón que predicó el padre Cos en la primera fase de la lucha por la independencia de México. En este artículo privilegiamos una lectura teológica del texto.

\section{I}

Es conocido que la Inquisición en México tuvo una posición beligerante en contra de la lucha insurgente durante todo el proceso de la independencia (1808-1821) (Torres, 2010, pp. 133-159). Con argumentos teológicos se había combatido la opción por la independencia política de México. La lucha política contra el Estado colonial español fue considerada un delito de fe. Para la Inquisición no se podía separar la fe católica de la política. El sermón del padre Cos se situaba en el mismo nivel, es decir, que no se podía separar la fe de la política pero en el sentido inverso. Cos usaba argumentos teológicos para justificar la lucha por la independencia política; por lo mismo, no es sorprendente que la Inquisición haya hecho grandes esfuerzos para condenar la doctrina de Cos.

En el Archivo Histórico Nacional de España se encuentra una caja con papeles prohibida por la Inquisición de México en el Consejo del 17 de abril de $1816 .{ }^{1}$ En un paquete de papeles sobre el jansenismo de los siglos XVII y XVIII se encuentra la proclama impresa de la Constitución de los Rebeldes de Rayón, titulada "Govierno Mexicano"; otra proclama conocida como el Manifiesto del Supremo Congreso Americano del 19 de junio de 1814, y la

${ }^{1}$ Inquisición. Leg. 4449, núm. 10. Archivo Histórico Nacional (AHN), Madrid. 
copia de una carta de Morelos al Supremo Congreso Americano en la cual se adhiere al mencionado manifiesto fechada el 5 de junio de $1814 .^{2}$ La carta contiene lo que nos interesa para este ensayo, es decir, la primera parte de un sermón del padre José María Cos predicado "en la hacienda de Santa Ana de los Lobos”, que fue remitido a la Inquisición por Diego Miguel Bringas y Encinas, quien desarrolló toda una teología a favor de la monarquía española y en contra de los insurgentes (Connaughton, 2010, pp. 160-200). No nos sorprende entonces que los sermones de Cos llamaban la atención de Bringas a tal grado que se volvió una obsesión para el inquisidor, y Bringas se ha vuelto una referencia importante cuando se habla de los sermones antiinsurgentes. ${ }^{3} \mathrm{El}$ mismo fray Bringas hizo el último elogio público a la Inquisición de México a finales de 1812 en su largo libelo en contra del manifiesto de Cos, argumentando que la Inquisición había dado la primera herida mortal al movimiento insurgente al catalogar a Hidalgo como el peor de los herejes el 13 de octubre de 1810 (Torres, 2004, p. 119). Bringas se volvió uno de los principales defensores del realismo y uno de los principales atacantes de José María Cos, aludiendo, en su famoso sermón antiinsurgente de acción de gracias por la victoria realista en Toluca en 1812, a Cos como "doctores presumidos de sabios" (Herrejón, 2003, p. 305).

La hacienda Santa Ana y Lobos -como se conoce hoy en día- está ubicada en el municipio de San Luis de la Paz en el es-

\footnotetext{
${ }^{2}$ Esa carta de Morelos del 5 de junio de 1814 fue publicada en Lemoine (1991, pp. 474-475).

${ }^{3}$ Para una semblanza de Bringas véase Herrejón (2003, pp. 184-185).
}

tado de Guanajuato. En aquel entonces pertenecía al Obispado de Valladolid. Lobos, la hacienda y su agregada de Santa Ana era conocida por su cría de ganado mayor y menor. Antes pertenecía a la Compañía de Jesús y fue expropiada a los jesuitas, como consta en la relación del virrey Bucareli de las fincas expropiadas en Nueva España que hizo para el conocimiento de los compradores el 25 de enero de $1773 .{ }^{4}$ No había un lugar más apropiado para el sermón rebelde del padre Cos, tomando en cuenta esa tradición de religión y política que irradiaba la hacienda.

José María Cos fue ordenado diácono en Valladolid el 19 de diciembre de 1795 por el obispo de Michoacán, junto con José María Morelos, quien recibió el subdiaconado. Cos nació en 1774 en la provincia de Zacatecas y tuvo toda su formación en Guadalajara; los documentos relativos a la "licenciatura y doctoramiento en sagrada teología del bachiller D. José María Cos y Pérez, presbítero de este obispado" fueron publicados en 1942 (Documentos, 1942, pp. 253-265). 5 Después de su ordenación como sacerdote fue nombrado catedrático de filosofía en el Colegio Seminario de Guadalajara a partir de 1798. En 1801 siguió su nombramiento como párroco del Mineral de la Yesca (en el actual estado de Nayarit) que no duró mucho, ya que de 1802 a 1810 fue párroco de Burgo de San Cosme (hoy Villa de Cos, en el estado de Zacatecas). Ya influyente, de 1809 a 1810 fue candidato a diputado a las Cortes de Cádiz por la provincia de Zacatecas, pero no ganó la elec-

\footnotetext{
${ }^{4}$ Publicada por Solano (1991) recuperado de http://biblio.jurídicas.unam.mx/libros

${ }^{5}$ Los documentos relativos a la titulación de Cos.
} 
ción y poco tiempo después se unió a la causa de Hidalgo. Antes de la sublevación del pueblo, Cos era conocido como un crítico del régimen colonial y su biógrafo hace referencia a sus prédicas contra el colonialismo español: "y en un sermón, se soltó tanto la lengua, que el escándalo llegó hasta las oficinas del propio Tribunal del Santo Oficio de México" (Lemoine, 1976, p. 10). Este sermón que evoca el doctor Lemoine Villicaña no fue pronunciado antes de 1810, sino después, cuando ya estaba avanzada la primera fase de la guerra por la Independencia, como se puede leer en el anexo I. Correctamente se ha señalado que no hay que enfocarse solamente en el contenido de un sermón insurgente sino en el uso del sermón (Ávila, 2010, pp. 17-39). El contexto de este texto de Cos fue la guerra de Independencia de Nueva España, una situación de insurgencia y contrainsurgencia, una guerra civil con el uso de terror y violencia, una guerra de liberación nacional donde se confrontaban las fuerzas del viejo orden colonial y grupos de insurgentes que contaban con la presencia de curas como Cos. El sermón de Cos no tenía como objetivo una disertación teológica sino fortalecer con el arma de la palabra una rebelión que no contaba con los recursos que tenían las fuerzas realistas.

La proliferación de sermones antiinsurgentes tuvo como reacción sermones insurgentes que casi no llegaron a imprimirse y que son pues desconocidos. Herrejón (2003) califica a los sermones antiinsurgentes dentro del género de la diatriba, que descalifica la posición política de ciertos grupos o personas cuyo "desarrollo espectacular se dio a partir de 1810 , con la guerra de Independencia" (p. 285). Los sermones antiinsurgentes y los sermones insurgentes definidos como sermones a favor de la insurgencia compartían un aspecto común: eran sermones contra Napoleón y Francia. Este tipo de prédicas, que tiene como objeto principal el ataque, la condena y la crítica de una posición política para que el auditorio rechace esa postura, no se había cultivado antes en Nueva España. El sermón de Cos, que vamos a ver más adelante, ataca la influencia liberal de la Francia revolucionaria en las reformas borbónicas en España, que abolieron la inmunidad clerical, y define al enemigo como el partido de Lutero. Los sermones antiinsurgentes defendían a la monarquía española y propagaban un odio a Napoléon y a los franceses. Los sermones insurgentes defendían la insurgencia y la autoridad de Hidalgo.

Eso marca la diferencia fundamental entre los sermones antiinsurgentes y los sermones insurgentes, que es la figura de Hidalgo y la causa de la independencia. Ya para el 15 de enero de 1811 se da a conocer un sermón antiinsurgente que lanza una extensa diatriba contra Hidalgo (Herrejón, 2003, p. 279). Y el sermón insurgente de Cos hace justo lo contrario: defiende los derechos de la Iglesia y por eso defiende la causa de Hidalgo. Precisamente esa es la razón que lleva a Herrejón (2003, p. 285) a calificar a los sermones insurgentes como un nuevo tipo de discurso, porque su intención fue la de defender una nueva causa. Los sermones insurgentes son definidos como la contrapartida de los sermones antiinsurgentes:

Sin duda fueron muchos los discursos sacros y semisacros que se pronunciaron en los territorios dominados por los rebeldes o por donde pasaban sus ejércitos y gavillas. Además de las prédicas de domingo y días 
festivos, que los insurgentes celebraban escrupulosamente, hubo sermones eventuales de arenga antes de las batallas de funeral por los caídos. De manera más recurrente o programada también se dieron prédicas en recuerdo de los primeros insurgentes y con motivo de las juras, primero, de la Suprema Junta de la propia insurgencia, y luego, de la Constitución de Apatzingán. Desgraciadamente casi ninguno se imprimió, a pesar del largo tiempo de más de siete años que duró el movimiento en actividad (Herrejón, 2003, p. 317).

Felizmente conocemos un sermón insurgente de Cos gracias a la Inquisición.

\section{II}

En el sermón del padre Cos es central la defensa de la inmunidad clerical. Para muchos historiadores la defensa del fuero eclesiástico fue el motivo principal de los curas insurgentes para preservar sus privilegios. Efectivamente, en 1795 la corona española abrogó la absoluta inmunidad del clero, aunque en la práctica se quedó en letra muerta hasta el periodo del virrey Francisco Xavier Venegas, quien inició sus labores el 14 de mayo de 1810 , y el 16 de septiembre 1810 Miguel Hidalgo lanzó el movimiento de independencia enarbolando el estandarte de la Virgen de Guadalupe. A partir de entonces la abolición de la inmunidad clerical se volvió un arma importante de la guerra antiinsurgente. Este resurgimiento del tema de la inmunidad clerical posiblemente pudiera explicar el contexto del texto de Cos. Pero no se puede interpretar el asunto de la inmunidad eclesiástica sólo como una cuestión de intereses personales de los curas. Al abolir la inmunidad absoluta del clero, los clérigos acusados de crímenes graves podían ser perseguidos por tribunales civiles o militares, por lo tanto no tenía sentido entonces para un sacerdote unirse a la insurgencia sabiendo que podía pagar con su vida. Debe haber un motivo más profundo, y por eso hay que plantear esta cuestión de la inmunidad en el contexto teológico de esa época. No fue casual que la Inquisición clasificara el sermón de Cos bajo la herejía del jansenismo.

En su excelente ensayo sobre el jansenismo español, David Brading (1991, p. 241) concluye sin embargo erróneamente que los curas insurgentes, por la influencia del jansenismo, perdieron su vocación religiosa y se volcaron hacia la actividad política y militar. Brading correctamente señala que los curas insurgentes fueron influenciados por el jansenismo, pero ignora que hay una tradición de siglos de sacerdotes-políticos que atraviesa diferentes épocas, sacerdotes que se lanzaron a la política motivados por su vocación religiosa. Si bien el jansenismo tenía influencia en Nueva España, sin embargo el contexto impuso nuevas características teológicas, como muestra el sermón de Cos, que es objeto de estudio de mi ensayo. Si se reivindicaba la Iglesia local frente al centralismo papal como tesis principal en el jansenismo español, en Nueva España la consecuencia lógica de esta afirmación era que carecía de toda legitimidad la donación de América que el papa había hecho a favor de la monarquía católica, y Cos entonces justificaba la opción por la insurgencia. Otra peculiaridad fue que la defensa de la inmunidad clerical se volvió un asunto teológico de suma importancia. La autoridad de la Iglesia local estaba teológicamente basada en 
el sacerdocio y no en el papado, y por eso la defensa de Cos de la inmunidad clerical significaba la defensa de la Iglesia local. Otra característica fue la importancia de la religiosidad popular. Si el jansenismo español despreciaba la religión popular, en el sermón de Cos se reivindicaba la religiosidad popular, especialmente la devoción a María de Guadalupe.

Las consecuencias son obvias: no sólo se vuelve un asunto teológico la lucha por la independencia, sino que esta nación independiente tenía que privilegiar a la Iglesia local y el sacerdocio. Por eso la Declaración de Independencia redactada en 1813 por el Congreso de Chilpancingo, que se realizó en la iglesia de Santa María de la Asunción de esa ciudad, privilegió a la Iglesia católica y prohibió las otras Iglesias. Hidalgo, Morelos y también Cos se lanzaron a la lucha política para defender la religión católica y la patria. Otro extraordinario sacerdote-político, quien no estaba ajeno al influyente jansenismo -Abbé Henry Grégoire, obispo de Blois en Francia-, llegó a una conclusión contraria a los sacerdotes insurgentes mexicanos: él se hizo republicano que defendía la separación Iglesia-Estado y la elección local de obispos y sacerdotes. Abbé Grégoire sufrió también la condena de herejía por Roma. En la historia de la teología en América Latina ocupa un lugar importante ese pensamiento teológico de los curas insurgentes, y es necesario hacer más estudios sobre la historia de la teología en México. ${ }^{6}$

\footnotetext{
${ }^{6}$ Churruca (1981, p. 271) señala que es necesario un estudio sobre una nueva corriente teológica que había empezado varios decenios antes de 1810 en Michoacán, Puebla, México, propiciado por jesuitas y que fue bautizado bajo el nombre de Teología Política Caritativa.
}

El sermón de Cos estaba plagado de alusiones teológicas. Hablaba del martirio en defensa de la inmunidad eclesiástica, y la palabra "martirio" tiene una connotación precisa en la tradición católica. Sólo son mártires los que ofrendaron su vida en defensa de la fe católica. Al aceptar la idea de martirio Cos reivindicaba la existencia de una guerra santa y eso explica las alusiones de Cos a la causa santa. El concepto de guerra justa está muy presente en la tradición católica. Desde San Agustín hasta Santo Tomás de Aquino se ha producido una teología de la guerra justa (Lampe, 1996, pp. 31-38). Para que una guerra sea justa debe haber un motivo justo y esa causa justa fue la independencia de México. Como Cos no reconocía al poder soberano de la monarquía, la autoridad que podía declarar una guerra justa era el sacerdote, en este caso el padre Hidalgo. Santo Tomás de Aquino argumentaba que sólo se podía justificar la violencia cuando se trataba de salvar el bien común luchando contra la tiranía, y por eso Cos insistía en que era una guerra contra los opresores.

Cos definía a los opresores como ateos, otro concepto teológico interesante. Hidalgo criticaba que los españoles adoraran al dios dinero y que sólo tenían por objeto la opresión de los americanos "víctimas de su insaciable codicia” (citado por Ibarra y Landavazo, 2010, p. 63). Este concepto teológico ya lo había usado Bartolomé de las Casas, obispo de Chiapas en el siglo XVI, quien afirmaba que los conquistadores no adoraban a Dios sino al oro en las Indias (véase Gutiérrez, 1992). El padre José María Cos decía que los españoles que saqueaban a la colonia de Nueva España adoraban al dios dinero y por lo tanto eran ateos porque no adoraban al Dios 
verdadero. Eran perseguidores de los ministros del verdadero Dios, porque perseguían a los sacerdotes rebeldes. Los ateos atropellaban la imagen de la Virgen de Guadalupe, eran perseguidores del verdadero Dios. Los sacerdotes rebeldes defendían al verdadero Dios.

Cos defendía al sacerdocio clerical en contraposición al sacerdocio del pueblo proclamado por el protestantismo. Con cierta reserva me atrevo a afirmar que el horizonte católico cerrado y no incluyente de Cos pudo haber sido la causa de su ruptura con el gobierno insurgente en julio de 1815 , y lo repito con cierta reserva porque sabemos muy poco del conflicto entre la dirigencia insurgente y algunos curas insurgentes, como fue el caso de Cos (Ibarra y Landavazo, 2010, p. 230). Lemoine Villicaña plantea la hipótesis de que, como Cos no consiguió ser nombrado agente diplomático en Estados Unidos por el gobierno independiente, decidió romper con este (Lemoine, 1996, p. LXXXIII). Eso sería desconocer su visión teológica del mundo, que llevó a Cos a unirse a la causa del padre Hidalgo y declararlo como un vil oportunista que únicamente buscaba sus intereses personales. Cos cuestionaba la decisión de la dirigencia insurgente de enviar un diplomático a Estados Unidos, porque temía una invasión de México por Estados Unidos que significaría la introducción de personas no católicas (Jiménez, 1999, p. 193). En la última etapa de su vida Cos vuelve a repetir ese argumento: "Que me opuse a sus designios de alianza con los angloamericanos" (Documentos, 1942, pp. 281-282). No hay que olvidar que Cos participó en la Constitución de Apatzingán, promulgada en 1814, que decretó que "la calidad de ciudadano se pierde por crimen de herejía, apostasía y lesa-nación”, es decir, un protestante no podía ser ciudadano mexicano (citado por Brading, 1991, p. 190). La requisitoria de Cos contra el Congreso dice:

han nombrado un plenipotenciario público a los Estados Unidos para conducir tropas extranjeras a este reino [...] Cómo en un asunto de tanta gravedad e importancia no se consulta la opinión pública para averiguar si los ciudadanos católicos de esta América querrán que sus hijas y esposas vivan y traten con aquellos extranjeros, sin tener consideración a la religión católica, que indefectiblemente se perdería con la mezcla de ateístas y protestantes? (Jiménez, 1999, pp. 199-200).

Decir que ese cuestionamiento de Cos venía de su frustración al no ser nombrado para ese cargo diplomático en Estados Unidos como sugiere Lemoine no puede ser la única y exclusiva explicación, porque no hay que enfocarse solamente en el interés personal de los curas para preservar sus privilegios como motivación de su involucramiento en la lucha por la independencia, sino que se volvió una guerra religiosa que los motivaba a estar al lado de los oprimidos y en contra de los opresores (Ibarra, 2010, p. 73). Defender la inmunidad del clero como hacía el sermón de Cos era defender a la religión del pueblo, porque sin el ministro no había culto y sin el culto el pueblo no podía cumplir con sus fiestas sagradas, lo que sería la omisión más grave en el imaginario popular. ${ }^{7}$ No sorprende entonces leer

${ }^{7}$ Fue el cura José Julio García Torres (17721831) quien en el sermón del 12 de octubre de 1821 , ya consumada la independencia, mostrando que los 
en un cañón, que pertenecía al ejército de Morelos, la inscripción: "Para defender la fe y la pureza de María Santísima."

Taylor (1999, p. 686) señala acertadamente que el título "Siervo de la Nación" que Morelos se dio a sí mismo es un concepto teológico parafraseando el "siervo del Señor”, que es una noción bíblica. Para Morelos él era un servidor de Dios y un servidor de la patria, que no había contradicción entre ser sacerdote y ser líder insurgente. Señala que hasta el final Morelos no se consideraba un sacerdote renegado sino un fiel sacerdote. No aceptó la excomunión ni la acusación de herejía. Para Morelos no había contradicción entre su cristianismo y su movimiento independentista. Proclamó la independencia nacional y la religión católica como única y exclusiva. Morelos, así como Cos y otros sacerdotes insurgentes, no solamente no cuestionaron la doctrina católica, sino que su catolicismo interpretado más como una ética social fue su inspiración para volcarse hacia la lucha insurgente. Su teología moral de caridad cristiana y sacrificio personal lo llevó hacia la justicia social, en la cual los ricos sean menos ricos y los pobres menos pobres favoreciendo así la igualdad social y, por eso, la protección de los derechos de los indios y la abolición de la esclavitud. Como cristiano tenía que practicar la caridad y como sacerdote profeta tenía que ser voz de los que no tenían voz, es decir, proteger al débil e indefenso, y esta combinación lo llevó a

decretos anticlericales de las Cortes españolas de 1820 llevaron a la victoria final del movimiento de independencia, pronunció aquellas palabras: "No hay, señores, religión sin culto, ni culto sin ministros, y atacados estos y aquel, es atacada la religión misma" (citado por Herrejón, 2003, p. 333). la praxis revolucionaria. Esa lectura teológica que hace Taylor de la praxis revolucionaria de Morelos nos hace entender mejor por qué es necesaria una lectura teológica del sermón de Cos. El sermón insurgente, como el de Cos, no era solamente un sermón político, como lo define Herrejón (2003, p. 22), distinguiendo este del sermón moral y del sermón teológico, sino que era al mismo tiempo un sermón político, moral y teológico.

III

El padre Cos se sitúa en una tradición muy larga de sacerdotes-políticos en la historia de la Iglesia católica (Lampe, 2013, pp. 223-239). La motivación del sacerdote-político respecto a su compromiso con la lucha política es su fe cristiana, porque no se puede separar la fe de la política. Lemoine Villicaña (1996, p. LXXXIII) definió la motivación del padre Cos para hacerse insurgente en su frustración por no habérsele permitido una carrera eclesiástica y, por el contrario, haber sido castigado al ser nombrado como párroco de parroquias sin importancia. Ese argumento de Lemoine Villicaña no cuadra con el hecho de que él mismo repite una y otra vez que el padre Cos defendía a la Iglesia dentro de su programa insurgente. Si fuera por frustración por la Iglesia, por qué la defendería, lo que indica que no es allí donde hay que buscar la motivación del padre Cos.

En el debate dado entre Alan Knight y Eric Van Young se puede decir que Knight (2004, pp. 445-515) tuvo razón en señalar que Van Young subestimó la participación de sacerdotes-políticos en el proceso de independencia de México. Es 
interesante que un experto en la historia militar de la época de la independencia de Nueva España, como es Christon Archer (2010), comente lo siguiente sobre la sección de nombres de curas insurgentes en la clásica obra de Taylor: "Si bien no puedo ofrecer estadísticas mejores en mis estudios militares de las intendencias de Valladolid, Guanajuato y México, estoy convencido que la proporción de clérigos, incluyendo curas, en el bando insurgente fue más grande que la que indica Taylor" (p. 158). Van Young (2004, pp. 517-573) argumentó que el proceso de independencia no fue una historia fomentada por curas rurales desleales. Una afirmación que por cierto no carece de fundamento, aunque no había que subestimar la influencia que ejercía el clero en la sociedad. En todo caso el debate se ha enfocado más hacia la importancia o no de la participación del clero que se puede medir sea por cifras o por la cuestión de la función de los sacerdotes como dirigentes en la insurgencia, y no tuvo suficiente atención en ese debate la motivación que llevó a esos sacerdotes a ser insurgentes, lo que es la perspectiva principal de mi trabajo.

En este último punto Van Young no ha mostrado ninguna sensibilidad por el aspecto teológico. Su visión reduccionista queda clara en su afirmación sobre los curas José Manuel Herrera, José María Cos, Mariano Matamoros, José María de San Martín, José Sixto Verduzco, todos sacerdotes que apoyaron la causa de los curas Hidalgo y Morelos: "las frustradas ambiciones profesionales y personales de estos hombres bien pueden haberlos impulsado a unirse a la insurrección" (Van Young, 2011, p. 461). Más adelante concluye Van Young que en los curas insurgentes "los motivos de una ideología supe- rior generalmente brillan por su ausencia” (p. 478), lo que muestra más bien una ausencia en la obra de Van Young de interés por alguna ideología teológica. Al analizar los casos de los padres Martín Diego de Soto, Francisco Lorenzo de Velasco y José Manuel Correa, el autor deja completamente de lado los motivos teológicos que llevaron a estos sacerdotes a asumir una postura insurgente (Van Young, 2011, pp. 391-392, y 513-543). Van Young (2011) comete otro error al afirmar:

La separación forzada de esta doble hélice de pensamiento político y religioso fue uno de los grandes objetivos sólo imperfectamente realizado de los forjadores de la nación y el Estado liberal mexicano (p. 791).

No es el único en la historiografía mexicana que confunde la separación IglesiaEstado con la separación fe-política. La separación Iglesia-Estado ha sido un logro histórico, pero en el cristianismo no se puede separar la fe de la política porque es la única religión donde su fundador fue condenado como rebelde político. ${ }^{8}$ Jean Meyer (1989, p. 27) también insiste una y otra vez en que la opción a favor de la independencia no era un asunto religioso, pero el sermón del padre Cos muestra lo contrario, que para Cos sí era un asunto religioso. La interpretación errónea de Meyer (1989, p. 342) sobre la separación de la Iglesia y el Estado como si esta necesariamente significara la reducción de la religión cristiana a la esfera privada, lleva a no poder entender a los sacerdotes insurgentes. El sermón del padre Cos muestra

\footnotetext{
${ }^{8}$ Para el significado de la cruz de Jesús de Nazaret véase Sobrino (1994).
} 
que para él la opción por la independencia de México fue una forma de ocuparse de la fe, fue una forma de hablar de Dios.

Para entender el sermón de Cos tendríamos que tomar en cuenta el horizonte bíblico que formaba parte de su "Weltanschauung". Hay un texto bíblico que expresa la prioridad de la fe cristiana: "nosotros creemos, por eso hablamos" (2 Cor. 4: 13). Cos, como Pablo a los Corintios, bien pudo haber dicho: creo, por eso me volví insurgente. No es por un interés mezquino de defensa de la inmunidad clerical, tampoco es por tener una doble vocación, una de sacerdote y otra de político, no es por revanchismo al ser asignado párroco de un pueblo insignificante. Fue la fe lo que lo motivó a arriesgar su vida por la causa de la independencia. Como lo expresó en diciembre de 1810 el padre Hidalgo sobre su motivación de optar por la independencia:

Cuando yo vuelvo la vista por todas las naciones del universo y veo que quieren gobernarse por individuos de su misma nación, no puedo menos creer que esta es una idea impresa en ella por el Dios de la Naturaleza.

La independencia como lex naturalis es una idea teológica para Hidalgo. ${ }^{9}$

Al terminar la primera fase de la guerra por la independencia mexicana en una derrota para los insurgentes, con una

\footnotetext{
${ }^{9}$ Hasta Ana Carolina Ibarra (2010), quien ha rescatado la motivación religiosa de los curas insurgentes, cae a veces en esa dicotomía: "no fue motivada por asuntos religiosos (se trató de motivos políticos, económicos y sociales)" (p. 52). Ella misma cita después un texto de Hidalgo que de nuevo realza su fe como motivación: "estoy pronto a derramar mi san-
}

insurgencia internamente dividida y diezmada, Cos regresó de la guerra vencido y desilusionado. No fue el único en la larga historia de sacerdotes-políticos que terminaron su vida en la amargura. En este contexto emocional de depresión hay que plantear otra etapa polémica en la vida de Cos. Gestionó su indulto en 1816 y en 1817 se acogió a la amnistía más amplia dirigida a los insurgentes que estuvieron ocultos o sometidos a proceso. ${ }^{10}$ La pregunta es si este gesto no era una prueba de su falta de coherencia y convicciones teológicas que tanto he enfatizado en este ensayo.

Cos no fue el único, sino que muchos de los curas insurgentes que sobrevivieron la primera fase de la guerra pudieron acogerse al indulto (Ibarra, 2010, p. 68). Además, muchas de las retractaciones de los líderes insurgentes eran falsas o arrancadas en artículo de muerte, así que el supuesto arrepentimiento de los que se acogieron al indulto fue bajo una enorme presión de circunstancias tan adversas que pone en entredicho si se puede hablar, en el caso de Cos, de un acto que fuera expresión de la libre voluntad. ${ }^{11}$ Otros investigadores acertaron en señalar que algunos

gre en defensa de cada uno de ellos", refiriendo a las verdades y dogmas de la Iglesia católica (p. 63).

${ }^{10}$ Para los documentos sobre el indulto de Cos, véase "Documentos" (1942, pp. 265-282).

${ }^{11}$ Ibarra (2010, p. 49) cita la confesión del cura insurgente José de San Martín, quien también se benefició del indulto: "protesto a toda la América, que si publiqué alguna retractación de mis opiniones, no le den ascenso, ni la crean. Estas retractaciones hechas en artículo de muerte, han sido uno de los embustes de los gachupines para crédito a su partido. Han fingido muchas veces y puesto en boca de nuestros héroes declamaciones y protestas de arrepentimiento, que jamás han sido capaces de concebir." 
aceptaron el indulto para evitar represalias, aunque no sintieron un arrepentimiento sincero, como bien pudo haber sido el caso del padre Cos (Ibarra y Landavazo, 2010, p. 84). En los documentos relativos al indulto de Cos hay un elemento de continuidad: su postura antiintervencionista, pues según él, una eventual invasión de Estados Unidos pondría en peligro la catolicidad de la nación mexicana ("Documentos", 1942, pp. 281-282).

A mi parecer, aunque no hay base documental sobre la intención del padre Cos, en total congruencia con sus convicciones teológicas Cos aceptó el indulto para poder seguir ejerciendo el ministerio sacerdotal. Lo que sí está documentado es que Cos, una vez libre después de haber sido encarcelado por las propias tropas insurgentes por haber chocado con la dirigencia y liberado por la junta militar de Uruapan que lo exoneró de los cargos que le formuló el disuelto Congreso, siguió militando en la insurgencia al lado de Rayón, y después del indulto fue de nuevo considerado sospechoso por las autoridades coloniales de haber participado en una conspiración en Pátzcuaro (Lemoine, 1996, p. LXXXVIII). ${ }^{12}$ Ser declarado de nuevo sospechoso podría indicar que Cos aceptó el indulto para poder seguir predicando a favor de la insurgencia, fiel a su vocación religiosa. En mi opinión especulativa, Cos escribió sus tres cartas de arrepentimiento, dos en 1817 y una en 1818, por razones tácticas, para evitar una brutal persecución que le impediría seguir con su ministerio sacerdotal. ${ }^{13}$

${ }^{12}$ Véase el acta que exoneró a Cos de toda culpa en José María Cos (1996, pp. 203-204).

${ }^{13}$ No estoy de acuerdo con las calificaciones más propias para un juez que para un historiador que ha
Vimos a lo largo de este artículo que el padre Cos no veía una contradicción entre ser ministro de Dios y haber tomado las armas en la guerra por la independencia y por eso, a mi parecer, después de haber servido en las tropas insurgentes, cuya misión quedó interrumpida, regresó al ministerio sacerdotal. Me imagino -y aquí hablamos de la imaginación de un novelista y no de un historiador- que fueron tres amargos años de ministerio sacerdotal, después de la derrota insurgente y de haber aceptado el indulto, antes de su muerte en 1819, a los 45 años de edad con un corazón deshecho y deprimido en una parroquia remota y olvidada. ${ }^{14}$

\section{CONCLUSIÓN}

El presente trabajo, que hace una lectura teológica de un sermón de José María Cos, sigue el ejemplo del historiador William Taylor (1999), quien en su clásica obra Ministros de lo sagrado (pp. 680-691) hace una lectura teológica de la praxis insurgente de José María Morelos. A diferencia de Taylor, en este artículo no uso el término de curas párrocos, sino el de sacerdotes políticos para mostrar la continuidad con una larga tradición católica de sacerdotes que al mismo tiempo tenían una praxis política. ${ }^{15} \mathrm{Mi}$ estudio, que rescata

usado Ernesto Lemoine Villicaña en cuanto a esta última etapa de la vida de Cos: casi criminal, mentiroso, falso (Lemoine, 1996, pp. LXXxIv, 209, 210).

${ }^{14}$ Esta idea especulativa se encaja más en una novela histórica al estilo de lo que hizo Jean Meyer (2011) sobre Hidalgo.

15 Taylor (1999, p. 680) menciona que más de una tercera parte de los delegados al Congreso de Chilpancingo en septiembre de 1813 fueron curas 
un sermón del padre Cos, está también acorde con la línea actual de la historiografía de la Iglesia y el clero en la independencia de México, tal como concluyen en su excelente reseña o balance bibliográfico los autores Ana Carolina Ibarra y Gerardo Lara Cisneros (2010):

que, hacia el nuevo milenio, los trabajos sobre cuestiones relacionadas con las ideas, posturas y pensamiento político del clero se valen de y apuntan cada vez más hacia la recuperación del discurso retórico en sus distintos momentos (p. 141).

Mi artículo se inserta en la nueva historiografía que se ha interesado por la religiosidad de los curas insurgentes, a diferencia de la historiografía tradicional que resaltaba más el pensamiento liberal/nacionalista (Ibarra y Lara, 2010, p. 129). En este sentido se puede considerar el presente trabajo como un aporte a la historia de la teología en América Latina, un campo de investigación todavía poco desarrollado. José María Cos fue un hombre de conflictos, y su figura tan controver-

párrocos, pero la pregunta es si ese término abarca a todos los curas insurgentes. Hay que distinguir a los curas seculares de los curas regulares, es decir los curas que pertenecen a una diócesis y los que pertenecen a una congregación u orden religiosa. En general los curas seculares eran párrocos de una parroquia, pero había curas regulares que no eran párrocos y que fueron insurgentes. Prefiero hablar de sacerdote político, como también ya es bien aceptado el término sacerdote obrero para referir al fenómeno del siglo xx cuando los sacerdotes se fueron a vivir y trabajar como obreros sin renunciar a su sacerdocio. Así, hay una larga tradición de sacerdotes del siglo XIX hasta el siglo XXI que se volcaron hacia la política sin dejar de ser sacerdotes y a los que denomino sacerdotes políticos. sial sigue siendo un misterio. No sin razón David Brading (1991) suspiró que "una interpretación convincente del papel desempeñado por el clero en el movimiento independentista sigue siendo un propósito difícil de alcanzar" (p. 214). Espero que esta lectura teológica del sermón del padre Cos y de su motivo de comprometerse con la lucha política haya avanzado un poco más en el camino de llegar a tal propósito.

\section{Anexos}

\section{El sermón de José María Cos}

La Iglesia Santa se halla atropellada por el partido que se nombre realista en sus tres inmunidades, local, real y personal. Los opresores con el más punible despotismo se han autorizado asimismo para decidir acerca del dogma de la disciplina eclesiástica manchando lo más puro de nuestra creencia con las negras doctrinas que enseñan públicamente en contra del sagrado sacramental, de la universal redención de Jesucristo, de los admirables efectos de la gracia, de la indefectible potestad sacerdotal y otras monstruosidades espantosas que sostienen en fuerza de sus armas.

Ellos se han supuesto legisladores para dictar leyes diametralmente opuestas a las establecidas por los romanos pontífices... Estos no tienen otro anhelo de perseguir al sacerdocio, promulgando al efecto bandos antieclesiásticos que inmediatamente vulneran tan santa inmunidad. Ellos en fin. Pero basta católicos... y veréis con espanto si la Iglesia Santa se halla afligida. ¿Quién de vosotros me negará sin temeridad que esos sacrílegos ateístas han incendiado los templos...? ¿Quién me 
contradecirá acerca de las imágenes atropelladas especialmente de María de Guadalupe lanceada en mi presencia y en la de millares de personas en Zacatecas el 17 de febrero de 1811? No han incurrido en esto nuestros perseguidores en una herejía declarada haciendo secuaces de los demonios? ¿Quién de vosotros duda que los edificios consagrados a Dios están sirviendo a nuestros opresores de Castilla y Baluartes en casi todos los lugares del Reyno? ¿Negadme pues, señores, que la Santa Iglesia está perseguida en su inmunidad local? Pero pasemos adelante...

Examinemos la real. ¡Felices lugares poseídos por los Americanos! Sólo en vosotros se conservan intactas las leyes destinadas por la piedad de los fieles al servicio del culto divino a Dios, a María y a sus santos católicos. Sólo en nosotros aunque estemos llenos de miserias ahora la resplandeciente antorcha de la religión de los pueblos desgraciados que poseen los perseguidores de Dios, y de sus semejantes, ya están contaminados con tan execrable sacrilegio. México, capital de este nuevo mundo, Guadalajara, Valladolid y demás ciudades van a ser testigos de esta irrefragable verdad...

Imploro que no me tengáis por parcial, siendo ministro del Altísimo...

¿Qué? ¿La muerte de los sacerdotes? ... Los ministros de Dios, los Dioses de la tierra: el sacerdocio rebelde, los dedicados pupilos del Altísimo... se han visto por los nominados Realistas en los patíbulos más espantosos, para ser ludibrio de los Bárbaros, admirándolos indiferentes irreligiosos egoístas, y asombro espantoso para los verdaderos católicos.

Lutero, Lutero: aborto fallido de la Alemania, ya resultó su seductora doctrina. Ya confundiste el sacerdocio con el pueblo.
Levanta otra vez sus banderas. Ya tienes de secuaces a casi todos los europeos españoles y ... (qué dolor, qué sentimiento) a multitud de Americanos, que por ignorancia... y por otras vergonzosas y depravadas pasiones siguen el partido Ateo.

Señores ya no puedo producir más en la materia, pero faltara a mis deberes Evangélicos si no condenara en este sagrado puesto al criminoso silencio de muchos que acaso me escuchan y que no sólo resisten defender la causa santa; sino que reducen a presto de vil interés para que otros se separen de tan acertados senderos. Diré con el Apóstol, absent a nobis, lejos de nosotros, estos tan ingratos a Dios y a la Patria. Ministros del Altar, operarios de Jesucristo: vosotros a quienes se os ha encomendado el cultivo de la viña del Señor, trabajad, trabajad, amorosos en defensa de los derechos de la Santa Iglesia. No temáis a los tiranos que sólo pueden quitar la vida del cuerpo, como una fiebre... o un rayón. Alentaos con magnanimidad... el delicioso plato del martirio en defensa de la inmunidad eclesiástica... ha de ser estable hasta la consumación de los siglos, a pesar de las instigaciones seductoras de nuestros perseguidores: non prevalebunt adversus mea.

\section{El dictamen del sermón de Cos por el Tribunal de la Inquisición}

“Asimismo juzgamos su sermón por una injuria horrenda sacrílega contra ambas potestades y sus más nobles individuos y principalmente contra Dios, cuyo nombre profana, cuyos atributos aplica erróneamente, cuyo honor deshonra y cuya Iglesia desfigura fanáticamente. Juzgamos además de las censuras... su sermón es 
digno de quemarse públicamente y su persona digna de las penas del Pabellón, sufriendo las de hereje...".

Decreto del Santo Oficio de México 4 de julio de 1815: "El Promotor Fiscal de este Santo Oficio dice que el sermón predicado por el rebelde doctor Cos en Santa Ana de Lobos y los demás papeles remitidos por el padre F. Diego Miguel Bringas están suficientemente calificados... Habiendo visto este expediente mandado formar con motivo de un sermón predicado por el rebelde doctor Cos y los demás remitidos por el reverendo padre F. Diego Miguel Bringas... que se inserte en el Primer Edicto su prohibición... así lo acordó, mandó y firmó..."

\section{LISTA DE REFERENCIAS}

-Archer, Ch. (2010). Historia de la guerra: las trayectorias de la historia militar en la época de la independencia de Nueva España. En A. Ávila y V. Guedea (coords.), La independencia de México, temas e interpretaciones recientes (pp. 145-161). México: UNAM.

-Ávila, A. (2010). Interpretaciones recientes en la historia del pensamiento de la emancipación. En A. Ávila y V. Guedea (coords.), $L a$ independencia de México, temas e interpretaciones recientes (pp. 17-39). México: UNAM.

-Brading, D. A. (1991). El jansenismo español y la caída de la monarquía católica en México. En J. Z. Vázquez (coord.), Interpretaciones del siglo XVIII mexicano (pp. 187-215). México: Nueva Imagen.

-Churruca Pelaez, A. (1981). El Pensamiento de Morelos. En P. Richard (ed.), Materiales para una historia de la teología en América Latina (pp. 219-271). San José, Costa Rica: CEHILA/DEI.

-Connaughton, B. (2010). ¿Politización de la religión o nueva sacralización de la política?
El sermón en las mutaciones públicas de 18081824. En B. Connaughton, Religión, política e identidad en la Independencia de México (pp. 160200). México: UAM.

-Documentos relativos al Insurgente Dr. José María Cos (1942). Memorias de la Academia Mexicana de la Historia, 1(3), 253-282.

-Gutiérrez, G. (1992). En busca de los pobres de Jesucristo. El pensamiento de Bartolomé de las Casas. Lima: CEP.

-Herrejón Peredo, C. (2003). Del sermón al discurso cívico. México, 1760-1850. México: El Colegio de Michoacán/El Colegio de México.

-Ibarra, A. C. (2010). El clero de la Nueva España durante el proceso de independencia 18081821. México: UNAM.

-Ibarra, A. y Lara Cisneros, G. (2010). La historiografía sobre la Iglesia y el clero. En A. Ávila y V. Guedea (coords.), La independencia de México, temas e interpretaciones recientes (pp. 117144). México: UNAM.

-Ibarra López, D. y Landavazo, M. A. (2010). Clero, política y guerra: la Independencia en la diócesis de Michoacán, 1810-1815. México: Instituto de Investigaciones Históricas-Universidad Michoacana de San Nicolás de Hidalgo.

-Jiménez Gassós, T. del C. (1999). José María Cos: ideólogo de la insurgencia mexicana. Xalapa, México: Editorial Biblioteca Universidad Veracruzana.

-José María Cos. Escritos políticos (1996). [Selección, introducción y notas de Ernesto Lemoine Villicaña]. México: UNAM.

-Knight, A. (2004). Crítica Eric Van Young, The Other Rebellion y la historiografía mexicana. Historia Mexicana, 54 (2:214), 445-515.

-Lampe, A. (1996). ¿Guerra justa o paz justa? Reflexiones teológicas sobre la lucha armada en Chiapas. México: Centro de Estudios Ecuménicos.

-Lampe, A. (2013). Political Celibacy. 1983 as a Turning Point in the Roman Catholic Church for Priests-Politicians. En C. Burlacioiu y A. Hermann (eds.), Veränderte Landkarten, Auf 
dem Weg zu einer polyzentrischen Geschichte des Weltchristentums (pp. 223-239). Festschrift für Klaus Koschorke zum 65. Wiesbaden: Geburtstag, Harrassowitz Verlag.

-Lemoine, E. (1976). José María Cos. Nuevos datos para su biografía. Estudios de Historia Moderna y Contemporánea de México, 5, doc. 42. IIH-UNAM.

-Lemoine, E. (1991). Morelos. Su vida revolucionaria a través de sus escritos y de otros testimonios de la época. México: UNAM.

-Lemoine, E. (1996). Estudio preliminar. En José María Cos. Escritos políticos [selección, introducción y notas de Ernesto Lemoine Villicaña] (pp. IX-XCI). México: UNAM.

-Meyer, J. (1989). Historia de los cristianos en América Latina, siglos XIX y XX. México: Editorial Vuelta.

-Meyer, J. (2011). Camino a Baján, una viva recreación de las batallas y la agitada travesía del cura Hidalgo en la independencia de México. México: Tusquets Editores.

-Sobrino, J. (1994). Jesucristo liberador. Lectura bistórico-teológica de Nazaret. México: Universidad Iberoamericana.

-Solano, F. de (1991). Cedulación de Tierras. Compilación. Legislación agraria colonial (1497-
1820). México: Instituto de Investigaciones Jurídicas-UNAM.

-Taylor, W. B. (1999). Ministros de lo sagrado. Sacerdotes y feligreses en el México del siglo XVIII (vol. II). Morelia: El Colegio de Michoacán.

-Torres Puga, G. (2010). Las dos supresiones de la Inquisición de México, 1813 y 1820. En B. Connaughton, Religión, politica e identidad en la Independencia de México (pp. 133-159). México: UAM.

-Torres Puga, G. (2004). Los últimos años de la Inquisición en la Nueva España México: CONACULTA.

-Van Young, E. (2004). De aves y estatuas: respuesta a Alan Knight. Historia Mexicana, 54 (2:214), 517-573.

-Van Young, E. (2011). La otra rebelión, La lucha por la independencia de México, 1810-1821. México: FCE.

\section{OTRAS FUENTES}

Archivo

AHN Archivo Histórico Nacional, Madrid, España. 